\title{
MTPA AND FLUX WEAKENING CONTROL OF PERMANENT MAGNET SYNCHRONOUS MOTOR FOR ELECTRIC VEHICLE
}

\author{
Guifang $M a$ \\ Longyan University, Fujian, China \\ Email: ma guifangsci2011@126.com
}

\begin{abstract}
In order to meet the wide application of current new energy vehicles, to break through the past vehicle battery technology, effective and reasonable drive control system is very important to improve the endurance of the vehicle. The key technology of permanent magnet synchronous motor control system for electric vehicles is studied. The maximum torque per ampere (MTPA) control of constant torque zone and constant power region weak magnetic control is discussed. A set of drive control system of permanent magnet synchronous motor for electric vehicle is developed based on 32-bit high performance micro processing chip TriCore1782. It has the peak power of $50 \mathrm{~kW}$, peak speed of $7000 \mathrm{r} / \mathrm{min}$, peak rotation of $160 \mathrm{~N} . \mathrm{m}$. The motor drive control system determines whether the electric vehicle can operate safely and reliably, and it is the core of the drive system. The drive system should have good torque control ability, high reliability and as high efficiency as possible in the range of speed regulation. Therefore, the development of highperformance motor drive control system has important engineering practice and guiding significance.
\end{abstract}

Keywords: Permanent Magnet Synchronous Motor, MTPA, Flux Weakening Control, Control System.

\section{Introduction}

The continuous development of the world economy has also made people pay more and more attention to the energy and environmental problems. In recent years, the severe haze weather in all parts of China has made the environmental problem become the focus of people's discussion [1]. As one of the most important sources of energy consumption and environmental pollution, the development of automobiles is also facing severe challenges. The traditional development model based on limited oil resources is becoming not recognized by people [2]. Energy conservation and environmental protection have become a new goal for the development of the automobile industry. In order to make more effective use of limited resources and energy, improve the utilization rate of resources and energy, and reduce the emission of toxic and harmful gases, so as to avoid further environmental pollution to human physical and mental health hazards, new energy vehicles emerge as the times require. Under this background, the development of new energy vehicles is widely appreciated. Because it can effectively avoid the dual crisis of energy shortage and environmental pollution, it is considered to be the core of the development of the automobile industry [3].
The permanent magnet synchronous motor is used as driving motor. Using the space vector pulse width modulation (SVPWM) technology [4,5], the maximum battery utilization rate is realized on the premise of the battery voltage limit of the electric vehicle. The maximum torque / current ratio (MTPA) is used to control the optimal combination of the intersection axis and the straight axis current, so that the stator current is minimized and the system efficiency is optimized. In order to meet the requirement of wide speed range of motor drive system in electric vehicles, a flux weakening control algorithm is designed to improve the speed range of motor. To verify the effectiveness of the control strategy designed, the vector control system of permanent magnet synchronous motor based on the rotor magnetic field orientation is built by Matlab/Simulink simulation software. In addition, the simulation research of the control system is carried out and the results are analyzed.

In order to verify the feasibility of the proposed control strategy, a set of permanent magnet synchronous motor drive control system for electric vehicles with 32-bit high performance micro processing chip TriCore1782 based on Infineon Corporation is developed, which has the peak power of $50 \mathrm{~kW}$, the peak speed of $7000 \mathrm{r} / \mathrm{min}$, and the peak torque of $160 \mathrm{~N}$.m. 
Through the Tasking programming environment, the software is studied in detail with the modular design idea, and the control flow chart and interface function of the main sub modules are designed.

Finally, based on the experimental platform, the constant speed loading experiment, the initial location verification experiment and the whole vehicle pavement experiment are completed, which verify the effectiveness of the designed scheme of the control system.

\section{Methodology}

The electronic control system mainly includes the battery management system, the motor control system, the energy feedback system, the electric power steering system and so on parts [6,7]. At present, under the premise of limited energy, in order to improve the dynamic response ability of the electric vehicle and the stability under the complex environment, and increase one charge and endurance travel of the electric vehicle, the technology of motor driven control is very important. The electric vehicle has its special requirements for the drive system: it is able to start, stop and decelerate frequently under various road conditions [8]. It needs rapid torque response ability; it keeps high operating efficiency in the whole range of operation; it works reliably in a bad working environment [9]. In the meanwhile, the system needs to achieve the actual technical requirement indexes. Therefore, it is very important for the reasonable design of the motor drive control system.

The principle and realization method of SVPWM are introduced. Then, the principle and realization process of the MTPA control method are analyzed in detail, and the automatic magnetic flux weakening control algorithm is analyzed theoretically. Finally, in accordance with the parameters of the motor, the vector control system model of permanent magnet synchronous motor based on magnetic field orientation is studied. The simulation research is carried out for the control model and the simulation results are analyzed.

The driving motor uses a three-phase built-in permanent magnet synchronous motor with a rated power rating of $50 \mathrm{~kW}$ and a rated speed of $3000 \mathrm{r} / \mathrm{min}$. The maximum speed of the motor is about $7000 \mathrm{r} / \mathrm{min}$, and the maximum output torque is 160 N.m.

\subsection{Principle of SVPWM}

SVPWM control is a pulse width modulation wave produced by a specific switching mode composed of six switching elements of a three-phase power inverter, so that the output current waveform is as close to the ideal sine wave as possible [10].

According to the principle of average value equivalence, the basic voltage vectors are combined in a switching period to make the average value equal to the given voltage vectors. Any voltage vector, in a certain area at certain moment, can be obtained by two adjacent non-zero voltage vectors and zero voltage vectors in different combinations of time. In a sampling period, the action time of each voltage vector can be controlled by applying the action time of the two voltage vectors for several times [11]. As a result, the trajectory is close to circular rotation, and the switching state of the inverter is determined by the comparison between the actual flux circle and the ideal flux circle, thus forming PWM waves.

The schematic diagram of the three-phase voltage inverter circuit is illustrated in Figure 1. The 3 bridge arms of the inverter are connected to the threephase windings of the permanent magnet synchronous motor, in which the VD1-VD6 is a continuous current feedback diode, providing a channel for feedback reactive energy. The VT1-VT6 is a power switch device, usually the IGBT or MOSFET fully controlled switch device [12].

The interruption of power switch devices is controlled by 6 switch signals, and the operation mode of the inverter circuit is 180 degrees conducting mode. When the permanent magnet motor is in normal operation, at any time, in order to make the motor three-phase winding simultaneously supply power, three devices with different bridge arms are connected, and the other three devices are turned off. If the upper bridge arm device connection is represented by the number " 1 " and the lower bridge arm device connection is expressed in number " 0 ", and they are sequenced according to the phase sequence of the abc three phases, then the working state of the inverter circuit has 8 kinds $(000,100,110,010,011,001,101,111)$, respectively [13], corresponding to the 8 basic space voltage vectors, respectively, as shown in Table 1 below. u1u6 represents 6 effective non-zero working vectors, and $\mathrm{u} 0$ and $\mathrm{u} 7$ represent 2 zero vectors, in which the amplitude of u1-u6 is equal [14]. There is a difference of $\pi / 3$ in space, the amplitude of the 2 zero vectors is zero, and Udc is the direct current voltage of the bus. Thus the distribution of the 6 sectors is shown in Figure 2. 


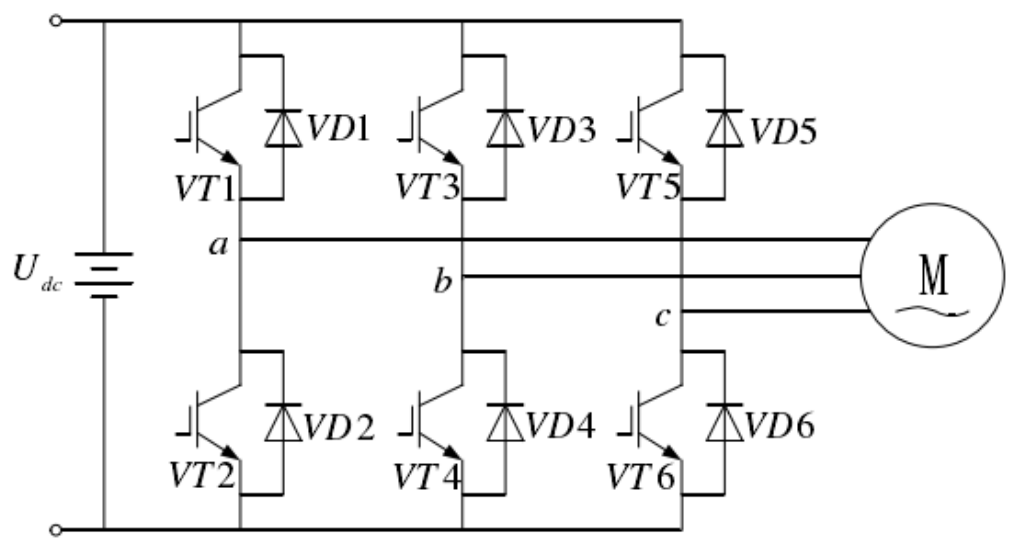

Figure. 1 Three-phase PWM voltage source inverter circuit schematic diagram

Table 1. Eight basic space voltage vector and the corresponding relations

\begin{tabular}{|c|c|c|c|c|c|c|c|}
\hline $\mathrm{z}$ & $\mathrm{S}_{\mathrm{c}}$ & $\mathrm{S}_{\mathrm{b}}$ & $\mathrm{S}_{\mathrm{a}}$ & $\mathrm{u}_{\mathrm{a}}$ & $\mathrm{u}_{\mathrm{b}}$ & $\mathrm{u}_{\mathrm{c}}$ & $\mathrm{U}_{\mathrm{S}}$ \\
\hline $\mathrm{u} 1$ & 0 & 0 & 0 & 0 & 0 & 0 & 0 \\
\hline $\mathrm{u} 2$ & 0 & 0 & 1 & $\frac{2 U_{d c}}{3}$ & $-\frac{U_{d c}}{3}$ & $-\frac{U_{d c}}{3}$ & $\frac{2}{3} U_{d c} e^{j 0}$ \\
\hline u3 & 0 & 1 & 1 & $\frac{U_{d c}}{3}$ & $\frac{U_{d c}}{3}$ & $-\frac{2 U_{d c}}{3}$ & $\frac{2}{3} U_{d c} e^{j \frac{\pi}{3}}$ \\
\hline $\mathrm{u} 4$ & 0 & 1 & 0 & $-\frac{U_{d c}}{3}$ & $\frac{2 U_{d c}}{3}$ & $-\frac{U_{d c}}{3}$ & $\frac{2}{3} U_{d c} e^{j \frac{2 \pi}{3}}$ \\
\hline $\mathrm{u} 5$ & 1 & 1 & 0 & $-\frac{2 U_{d c}}{3}$ & $\frac{U_{d c}}{3}$ & $\frac{U_{d c}}{3}$ & $\frac{2}{3} U_{d c} e^{j \pi}$ \\
\hline $\mathrm{u} 6$ & 1 & 0 & 0 & $-\frac{U_{d c}}{3}$ & $-\frac{U_{d c}}{3}$ & $\frac{2 U_{d c}}{3}$ & $\frac{2}{3} U_{d c} e^{j \frac{4 \pi}{3}}$ \\
\hline $\mathrm{u} 7$ & 1 & 0 & 1 & $\frac{U_{d c}}{3}$ & $-\frac{2 U_{d c}}{3}$ & $\frac{U_{d c}}{3}$ & $\frac{2}{3} U_{d c} e^{j \frac{5 \pi}{3}}$ \\
\hline $\mathrm{u} 8$ & 1 & 1 & 1 & 0 & 0 & 0 & 0 \\
\hline
\end{tabular}

In Figure 2, in a sector, two adjacent basic voltage vectors $\left(U_{x}, U_{x+60}\right)$ are selected to synthesize any voltage vector $\mathrm{U}_{r e f}$ in the sector. Based on the principle of volt second equilibrium, the expression of the voltage vector $\mathrm{U}_{\text {ref }}$ is as follows:

$$
U_{r e f}=\frac{T_{1}}{T_{x}} U_{x}+\frac{T_{2}}{T_{x}} U_{x+60}
$$

In Formula (1), Tx is the switching frequency period of PWM, T1 and T2 are the action time for two adjacent basic space vectors, and T0 is zero voltage vector action time. Then, the expression of action time $\mathrm{T} 0$ is as follows:

$$
T_{0}=T_{x}-T_{1}-T_{2}
$$

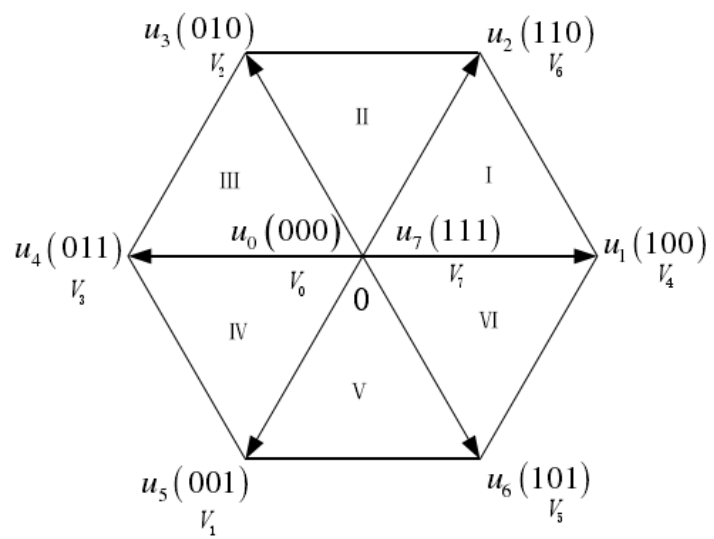

Figure. 2 Distribution diagram of voltage vector corresponding sector 


\subsection{Control strategy analysis of permanent magnet synchronous motor}

The essence of the permanent magnet synchronous motor vector control is to control the phase and amplitude of the stator current vector. The size of output electromagnetic torque depends on the current component of the motor stator current on the direct axis. In other words, the size of the motor output electromagnetic torque can be controlled by controlling the current of the direct axis. In order to improve the speed range of motor operation, a proper flux weakening control scheme should be adopted. The following are the detailed analysis of the MTPA control and flux weakening control strategy adopted in this project.

The MTPA control: in the control system, for each determined electromagnetic torque, there is a variety of axis current combinations corresponding to it. The selection of MTPA control strategy can make the electric vehicle output larger torque under the same condition. By controlling the optimal combination of the intersection axis and the direct axis current, the loss of copper can be reduced to the lowest value at this time. The control system reduces the capacity requirement of the inverter and achieves the best transmission efficiency.

When the motor runs stably, the calculation formula of electromagnetic torque is

$$
T_{e}=n_{p}\left\lfloor L_{m d} i_{f} i_{s} \sin \beta+0.5\left(L_{d}-L_{q}\right) i_{s}^{2} \sin 2 \beta\right\rfloor=n_{p}\left[\psi_{f} i_{q}+\left(L_{d}-L_{q}\right) i_{d} i_{q}\right]
$$

In Formula (3), $n_{p}$ refers to pole logarithm of motor, $\psi_{f}$ indicates magnetic chain of permanent magnets, $i_{x}$ suggests stator current, $i_{f}$ means equivalent excitation current of permanent magnets, and $\mathrm{L}_{\mathrm{d}}$ and $\mathrm{L}_{\mathrm{q}}$ are $\mathrm{d}$ and $\mathrm{q}$ axis inductance of the stator windings, respectively. Lmd and Lmq are the mutual inductance of $\mathrm{d}$ and $\mathrm{q}$ axis between fixed rotors, and $\beta$ is the spatial electric angle between the stator flux and the air gap magnetic field.

When MTPA is used to control, the current vector should satisfy the following formulas.

$$
\begin{aligned}
& \left\{\begin{array}{l}
\frac{\partial\left(T_{e m} / i_{s}\right)}{\partial i_{d}}=0 \\
\frac{\partial\left(T_{e m} / i_{s}\right)}{\partial i_{q}}=0
\end{array}\right. \\
& i_{s}=\sqrt{i_{d}^{2}+i_{q}^{2}}
\end{aligned}
$$

When MTPA control is used, the variation of the stator current component is shown in Figure 3.

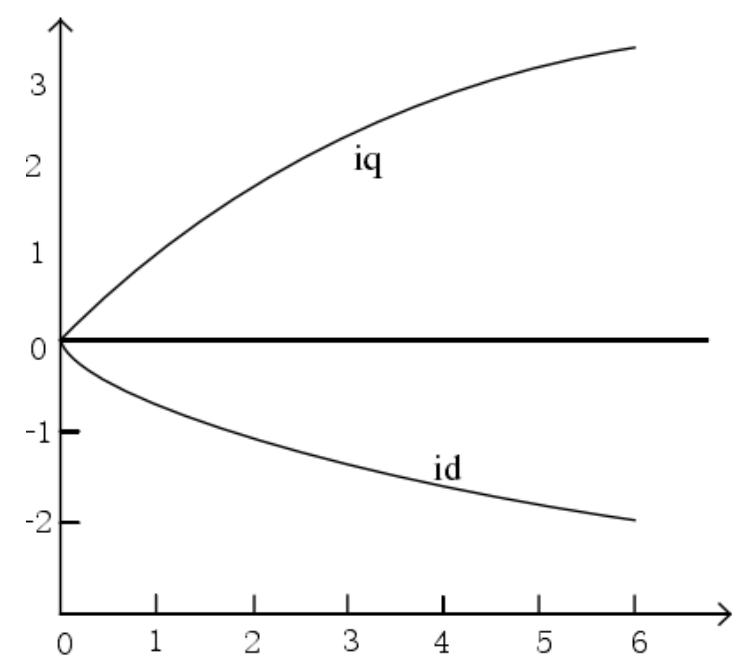

Figure.3 Motor stator current component trajectories with MTPA control
Principle and implementation of weak magnetic control strategy: in the course of driving, with the improvement of motor speed and the increase of torque, the end voltage of the motor will also increase gradually. At this time, the back electromotive force of the motor will increase with the speed of the motor. When the terminal voltage of the motor reaches the limit value of the output voltage of the inverter, there is no voltage drop between the motor and the inverter. Unable to continue to increase, the motor speed cannot be raised and the torque cannot be output. Therefore, a suitable method of weak magnetic control must be chosen to achieve a wide range of high speed and stable operation of the motor.

When the vector control system of permanent magnet synchronous motor is driven by a threephase voltage source inverter, the SVPWM modulation strategy is adopted. According to its principle, it is known that the maximum voltage value of the drive system is $U_{\max }=U_{d c} / \sqrt{3}$, and the maximum operating speed is limited by the maximum voltage that the inverter can output.

The maximum voltage and maximum current of the motor are:

$$
\begin{aligned}
& u_{d}^{2}+u_{q}^{2} \leq u_{\max }^{2} \\
& i_{d}^{2}+i_{q}^{2} \leq i_{\max }^{2}
\end{aligned}
$$

When the motor is running in steady state, the voltage equation is expressed as follows:

$$
\begin{aligned}
& U_{d}=R_{s} i_{d}-\omega_{r} L_{q} i_{q} \\
& U_{q}=R_{s} i_{q}+\omega_{r} L_{d} i_{d}+\omega_{r} \psi_{f}
\end{aligned}
$$




\subsection{Control strategy analysis of permanent magnet synchronous motor}

Through the analysis and study of the control strategy of the drive system, combined with the actual project background and the motor related parameters, the MTPA under the rated speed of the motor is controlled. The weak magnetic control is adopted above the rated speed to realize the weak magnetic speed regulation and the maximum power output of the motor in the full operation model. In order to make the simulation system model consistent with the actual project, a speed and current double closed-loop speed control system is built according to the engineering design method.

The control idea is as follows: in the speed control mode, the PI adjustment of the speed ring is carried out according to the difference between the given speed instruction and the actual speed of the motor feedback. The adjusted output is used as the current torque instruction value; in the torque control mode, the given torque is the current torque instruction value. Under the rated speed, MTPA control is used to get the given value of the direct axis current and the cross shaft current, respectively.

Then, the current PI is adjusted with the actual value of the motor to output the voltage of the straight axis and the cross axis. In the current regulator, it is necessary to limit the voltage of the voltage of the straight axis and the cross axis. Subsequently, Park inverter transformation and SVPWM modulation are carried out. At the same time, according to the three-phase current of the motor through Clark transformation and Park transformation, the actual value of the electric current of the motor is calculated.

The actual rotating speed value of the motor is calculated by the readings of the rotating transformer to participate in the adjustment of the speed loop and the current ring, thus realizing the double closed loop control of the speed and current. Above the rated speed, the weak magnetic control is adopted to compare the voltage limit with the amplitude of the modulated voltage. Through the integral control link and the amplitude limiting link, the given component of the direct axis of the stator current under the condition of weak magnetic field can be obtained. Joint with the direct current component of the torque output, it is used as a given value of the straight axis current, thus achieving weak magnetic control.

According to the mathematical model of the studied control system, the system simulation is conducted. Various parameters can be easily changed in the process of computer simulation. It can not only save a lot of time for the actual debugging, but also reduce the cost of production.

The simulation model of permanent magnet synchronous motor vector control system is built in Matlab/Simufink environment combined with motor parameters in practical engineering. The simulation models of SVPWM module, MTPA control, weak magnetic control algorithm, current regulator module and speed torque control module are analyzed, respectively. The simulation block diagram of the whole system is shown in Figure 4. Discrete time control method is adopted to simulate the system, and the sampling time is $\mathrm{T}_{\mathrm{s}}=2 \mathrm{e}-6$.

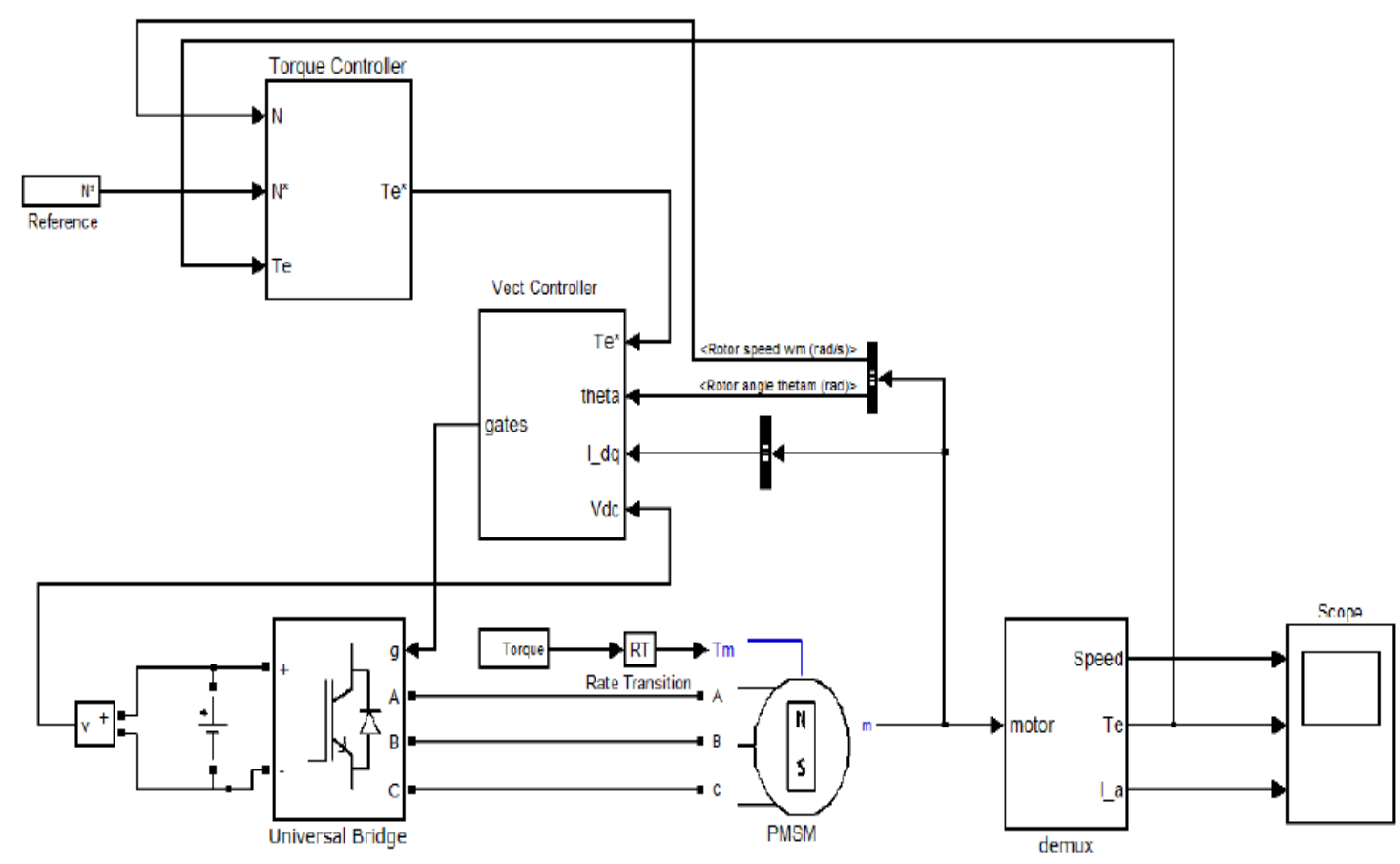

Figure.4 Simulation block of control system 
The simulation diagram of speed torque control is shown in Figure 5.

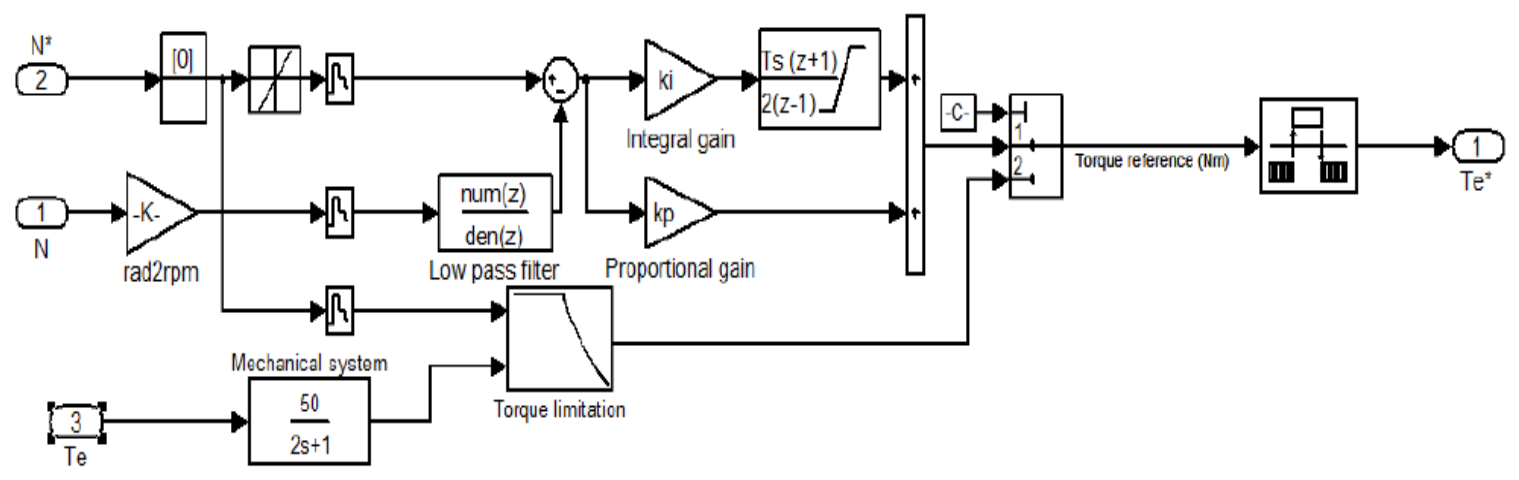

Figure. 5 The simulation diagram of speed torque control

\subsection{Vehicle pavement experiment}

In order to ensure the high reliability and high safety of electric vehicles in the course of driving, road test is needed to verify the performance of the driving system. In the vehicle pavement experiment, the experimental model of the electric vehicle is determined first, and then the motor controller is installed to the electric vehicle to carry out the experiment of the road surface.
For example, Figure 6 is the physical diagram of the motor drive controller developed. Figure 7 is a front mounting diagram for the drive controller.

The function of the anti-slip slope, the function of false gear, the speed of the cruise and the energy feedback control are verified separately in the experiment of the whole vehicle pavement, and the effectiveness of the control function is verified by the comparison and analysis of the data records.

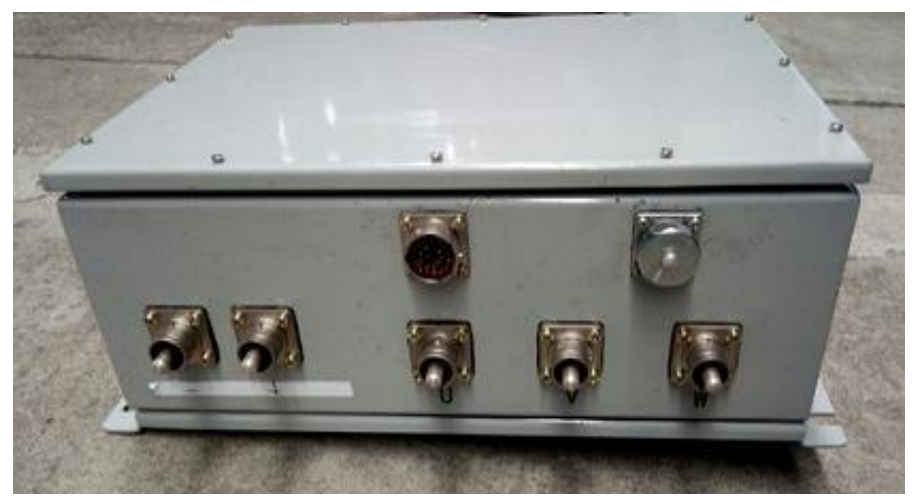

Figure. 6 Motor drive controller really picture

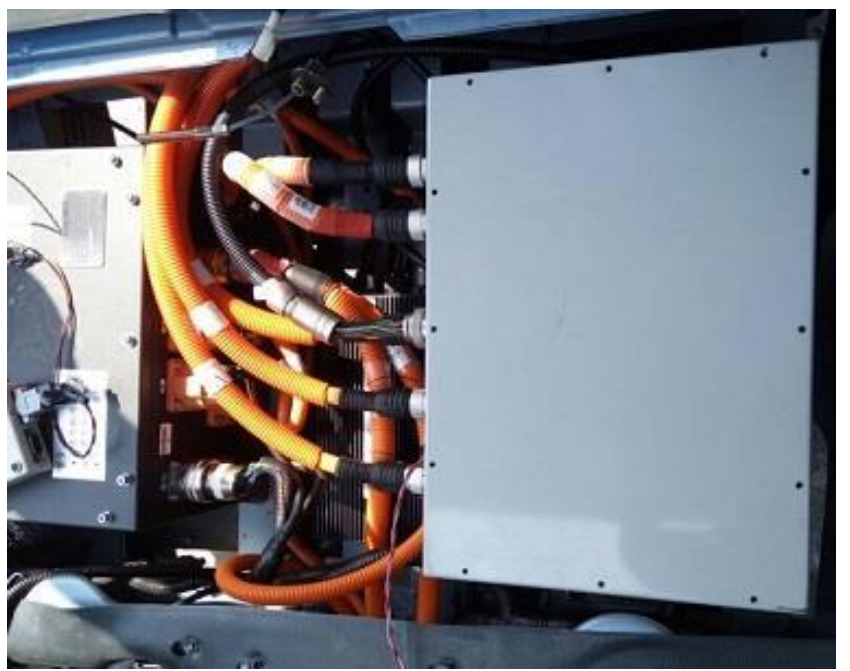

Figure. 7 Drive controller front installation 
In the pavement experiment, the key information of the electric vehicle and the controller should be observed. On the electric vehicle dashboard, the key information such as current battery voltage, battery power, bus current, vehicle speed, gear signal, fault signal and so on, can be easily monitored and recorded in real time.

The interior diagram of the electric vehicle is shown in Figure 8, and the road test stop diagram of the electric vehicle is shown in Figure 9.

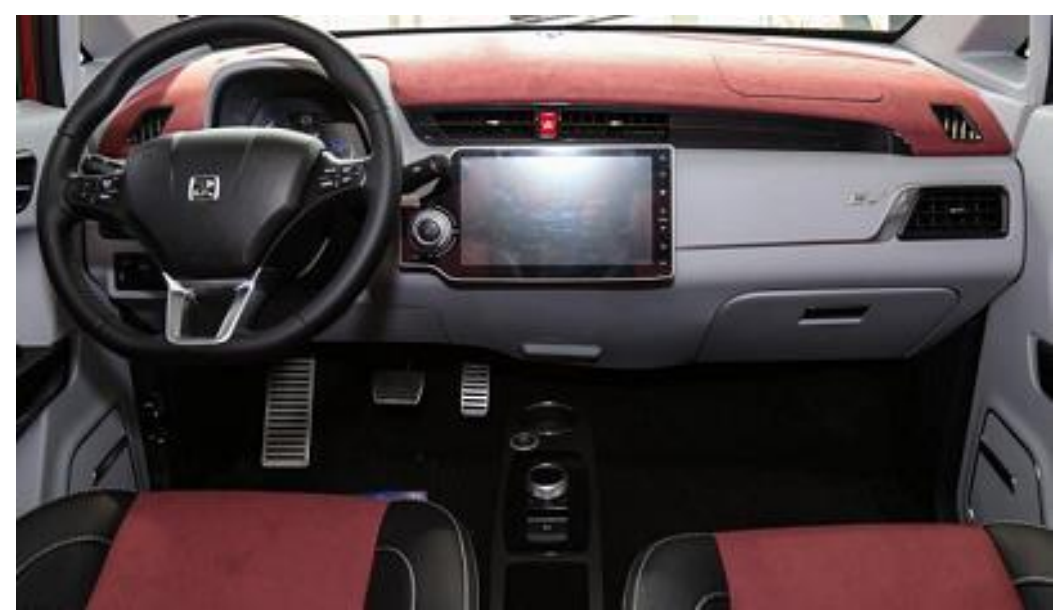

Figure. 8 Interior picture of electric car

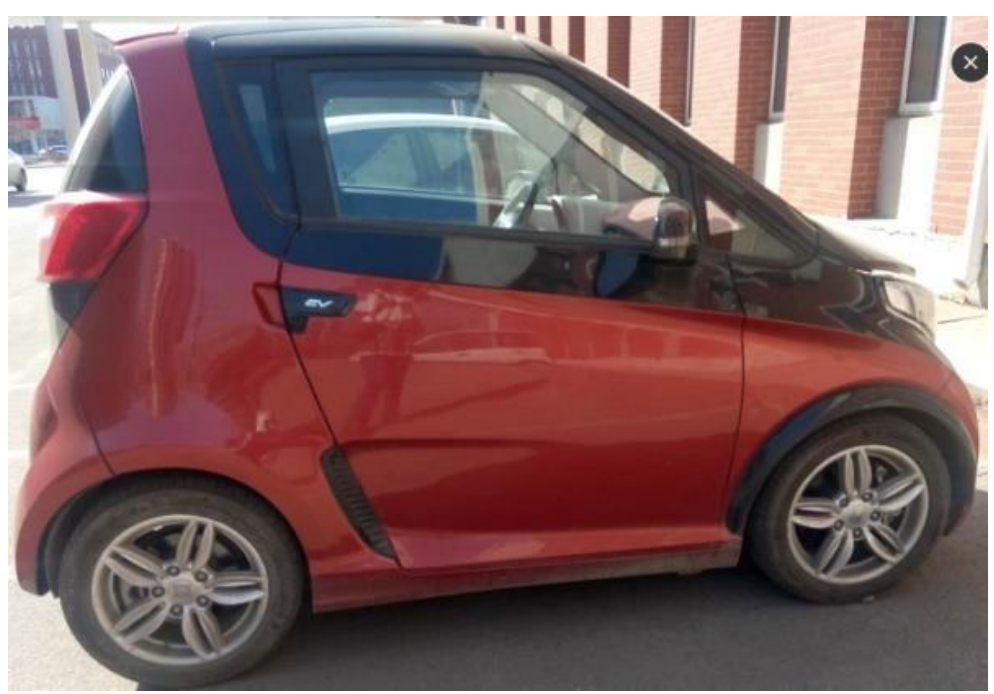

Figure. 9 Experimental of electric vehicle road

\section{Results and Discussion 3.1 Simulation results of rated torque and peak torque}

In order to verify the feasibility of the control algorithm proposed, the simulation analysis is carried out when the rated torque is $90 \mathrm{~N} . \mathrm{m}$ and the peak torque is $160 \mathrm{~N} . \mathrm{m}$, and the system simulation time is $2 \mathrm{~s}$. At $0.245 \mathrm{~s}$, the motor speed reaches the rated speed of $3000 \mathrm{r} / \mathrm{min}$; at $0.162 \mathrm{~s}$, the motor speed reaches the rated value. Lower than the rated speed, the torque is constant, and the fluctuation range of the torque is $3 \mathrm{~N} . \mathrm{m}$. When the motor speed continues to rise, the weak magnetic control is carried out, and finally the rotor speed is raised to the stable value. The effectiveness of the MTPA control and the weak magnetic control algorithm is verified. Because the simulation process contains too much data, the phase current curve of the motor is locally amplified. When the peak torque is $160 \mathrm{~N} . \mathrm{m}$, the stator current waveform at $0.1 \mathrm{~s}-0.13 \mathrm{~s}$ is displayed as a standard sine wave as a whole.

\subsection{Simulation results of constant speed loading}

In order to better imitate the actual system, to verify the effectiveness of control strategy and to carry out the simulation results analysis of constant speed loading of motor, the motor speed of $500 \mathrm{r} / \mathrm{min}$, $1000 \mathrm{r} / \mathrm{min}$ and $3000 \mathrm{r} / \mathrm{min}$ is added with $30 \mathrm{~N} . \mathrm{m}$ torque at $0.2 \mathrm{~s}, 50 \mathrm{~N} . \mathrm{m}$ torque at $0.5 \mathrm{~s}, 90 \mathrm{~N} . \mathrm{m}$ torque at $1.0 \mathrm{~s}$ and $160 \mathrm{~N} . \mathrm{m}$ torque at $1.5 \mathrm{~s}$.

When the motor speed is $500 \mathrm{r} / \mathrm{min}$, the stator current varies with the torque. In the range from 0 N.m to 160 N.m, the load torque increases, and the 
stator current increases. The stator current can quickly track the dynamic change of the torque, the waveform sine wave is good, and the fluctuation range of the torque is $\pm 1.5 \mathrm{~N} . \mathrm{m}$.

\subsection{Experimental results of whole vehicle pavement}

Verification of antiskid slope function: in the road test, the electric vehicle is placed on a safe road with a slope greater than 30 degrees. The electric vehicle first hangs the forward gear (D gear) and then loosens the hand brake and foot brake pedal. After the electric vehicle slightly backward moves about 5$10 \mathrm{~cm}$, the electric car can keep 10s still. Treading the accelerator pedal within $10 \mathrm{~s}$, the electric vehicle naturally climbs up the slope.

Verification of false gear function: in the false gear function verification, when the motor vehicle speed is higher than the set value of $5 \mathrm{Km} / \mathrm{h}$, the gear shift is judged to be a false gear mode, the gear failure becomes empty, and the electric vehicle has no power when stepping on the accelerator. Only when the gear signal is again hung back, the signal number is updated to a valid state and the motor driven controller outputs the torque.

Verification of speed cruise function: when the electric vehicle is driving on the road with good condition, if the current speed is $60 \mathrm{Km} / \mathrm{h}$, the speed of the cruise is enabled, the electric vehicle will not be stampede to keep the current fixed speed, and the speed of the car is observed in a set time. In the ideal condition, the speed of the vehicle can keep $60 \mathrm{Km} / \mathrm{h}$ steadily. Under the constant speed cruise mode, the speed threshold is $40 \mathrm{Km} / \mathrm{h}-110 \mathrm{Km} / \mathrm{h}$. Similarly, the road test is carried out at different vehicle speeds.

Effective verification of energy feedback control function: in the road test, the energy feedback control function is tested and verified. The test method is that the same electric vehicle drives the same distance in the same section. Under the premise of the same battery group and vehicle condition, in the two control systems of the original vehicle and that in the subject, the battery power before and after running of electric vehicles is measured. In order to fully verify the performance of the control system designed, the two-stage road experiment comparison is carried out on the road with good conditions and low braking frequency and the road with poor conditions and high braking frequency, continuing for 8 days, and the road test is conducted every day. It is clear from the test results that, no matter under the condition of good road condition and low braking frequency or poor road condition and high braking frequency, the energy feedback control function drive system designed is obviously better than the original electric vehicle control system without using energy feedback.

Therefore, the experimental results show that the motor controller with energy feedback function designed here can effectively improve the energy utilization and increase the driving range of the first charge of the electric vehicle.

\section{Conclusion}

The motor drive control system for electric vehicle with 32-bit high performance micro processing chip based on Infineon Corporation is developed. It has the peak power of $50 \mathrm{~kW}$, the peak speed of $7000 \mathrm{r} / \mathrm{min}$ and the peak torque of $160 \mathrm{~N}$.m, and the vector control and high speed magnetic flux weakening of the permanent magnet synchronous motor are realized. The core algorithm of the software is designed in detail. To sum up, the main conclusions obtained are as follows:

On the basis of the SVPWM technology, the MTPA control and weak magnetic control, the simulation model of the permanent magnet motor vector control system based on the rotor magnetic field orientation is built. The simulation research is carried out on the system, the high speed stable operation of the motor weak magnetic field is realized, and some key parameters of the actual control are determined, which provides the basis and guidance for the debugging of the actual motor drive control system.

The initial position of the rotor is detected by the symmetry method, which overcomes the problem of insufficient detection precision in the initial position of the rotor at high speed. It has low cost and high reliability, and improves the output performance of the control system.

The failure problems and causes of the controller are analyzed profoundly and the control ideas and methods are designed, which efficiently improves the reliability of the drive system. The functions of anti-skid slope, false gear, speed cruise and energy feedback control are designed, so that it can effectively avoid all kinds of safety problems caused by the improper operation of the driver, ensure the safety of the electric vehicle in the course of driving, and improve the driving range of the first charge of the electric vehicle.

The vehicle level chip TriCore1782 of the Infineon Corporation is used as the main control chip of the system, the software adopts the modular design idea, and the C language is programmed under the Tasking environment. Moreover, the experimental debugging is carried out through the on-line debug simulator of the German PLS company. Then, a set of motor drive control system for electric vehicle is developed, which has the peak power of $50 \mathrm{~kW}$, the peak speed of $7000 \mathrm{r} / \mathrm{min}$ and the peak torque of 160 N.m. The actual vehicle road test verifies the performance index and function of the motor drive control system developed here.

Through a period of research, some achievements have been made, but there is still a lot of work to do. 
Due to the limited time, the developed motor controller has only completed about 5000 kilometers of pavement experiment. But in the actual road conditions, there will be a variety of complicated situations, which are difficult to fully simulate. For mass production, it is also necessary to carry out a variety of simulation tests of more mileage.

Although the developed PMSM vector control system has solved some practical problems in the aspects of MTPA control, weak magnetic control algorithm, initial positioning, controller protection, driver intention and so on, the stability and reliability of the drive system still need to be further improved.

\section{References}

[1] Inoue, T., Inoue, Y., Morimoto, S., \& Sanada, M. (2015). Mathematical model for mtpa control of permanent-magnet synchronous motor in stator flux linkage synchronous frame. IEEE Transactions on Industry Applications, 51(5), 3620-3628.

[2] Zhang, B. Z., \& Ruan, Y. (2014). The research on interior permanent magnetic synchronous motor mtpa control. Applied Mechanics \& Materials, 644-650, 211-214.

[3] Schoonhoven, G., \& Uddin, M. N. (2016). Mtpaand fw-based robust nonlinear speed control of ipmsm drive using lyapunov stability criterion. IEEE Transactions on Industry Applications, 52(5), 4365-4374.

[4] Lin, F. J., Hung, Y. C., Chen, J. M., \& Yeh, C. M. (2014). Sensorless ipmsm drive system using saliency back-emf-based intelligent torque observer with mtpa control. IEEE Transactions on Industrial Informatics, 10(2), 1226-1241.

[5] Liu, X., Jiang, X. J., \& Li, L. F. (2013). Research on charging and discharging strategies of flywheel energy storage system using permanent magnet synchronous motor. Applied Mechanics \& Materials, 392, 576-581.

[6] Liu, T., Chen, G., \& Li, S. (2015). Research on control strategies of pmsm in electric state for hybrid electric vehicles. Open Automation \& Control Systems Journal, 6(1), 1697-1704.

[7] Fu, P., Zhen, C., Cong, B., \& Jing, Z. (2013). A position servo system of permanent magnet synchronous motor based on back-stepping adaptive sliding mode control. Transactions of China Electrotechnical Society, 28(9), 288-293.

[8] Petrov, I., Polikarpova, M., \& Pyrhonen, J. (2013). Rotor surface ferrite magnet synchronous machine for generator use in a hybrid application - electro-magnetic and thermal analysis, 20(11), 3090-3095.

[9] Chen, Y., Chen, X., \& Shen, Y. (2018). On-line detection of coil inter-turn short circuit faults in dual-redundancy permanent magnet synchronous motors. Energies, 11(3), 662.

[10] Glowacz, A. (2015). Diagnostics of synchronous motor based on analysis of acoustic signals with the use of line spectral frequencies and k-nearest neighbor classifier. Archives of Acoustics, 39(2), 189-194.

[11] Okuyama, Y., Tanaka, T., \& Hanamoto, T. (2013). A new current vector control method of ipmsm in flux weakening region to prevent inverter voltage saturation. Ieej Journal of Industry Applications, 2(6), 315-322.

[12] Chen, Y., Zhai, W., \& Shen, Y. (2015). Analysis on temperature field distribution of dualredundancy pmsm. Journal of Tianjin University, 48(6), 488-493.

[13] Ayyar, D. K., \& Abraham, A. M. (2014). High torque low current starter system for synchronous motor. International Journal of Computer Trends \& Technology, 7(2), 52-56.

[14] Li, H., \& Tao, C. (2017). Demagnetization fault diagnosis and fault mode recognition of pmsm for ev. Transactions of China Electrotechnical Society, 32(5), 1-8.

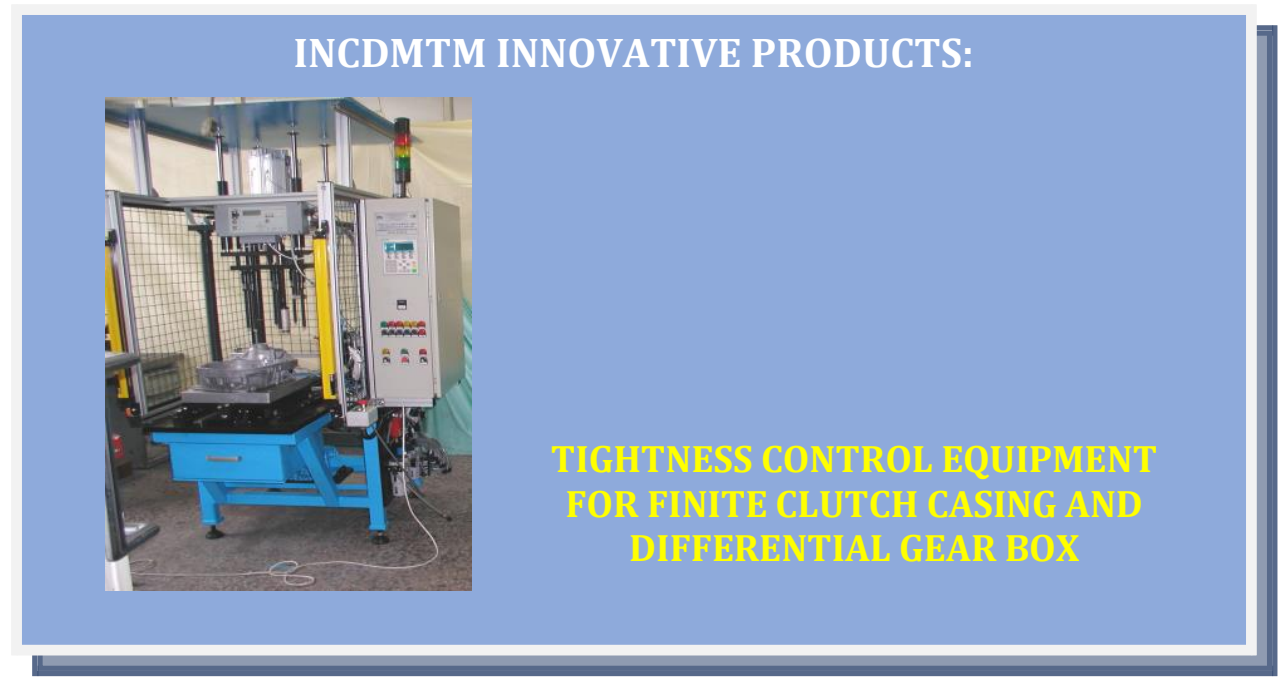

